\title{
Os desafios da conservação da arte pública no âmbito urbano: o caso da Fonte Monumental de São Paulo, Brasil
}

\author{
Regina Andrade Tirello, Alice de Almeida Américo
}

\begin{abstract}
Resumo: A cidade de São Paulo conforma território de múltiplos valores e vicissitudes decorrentes das alterações de uso dos espaços públicos, interferindo diretamente na conservação material de seu acervo de obras públicas. Compartilhando o espaço com outros elementos urbanos sempre renováveis, as obras artísticas, assim como a sua ambiência se atualizam para os fruidores; podem ser preservadas ou destruídas. Analisando o processo degradativo e as categorias de ação conservativa operadas na Fonte Monumental da Praça Júlio Mesquita (1927), da escultora Nicolina Vaz, esse artigo objetiva suscitar reflexões sobre a efetividade das operações de conservação física das esculturas públicas como ato desconectado da leitura das mudanças de uso dos espaços. Pesquisas arquivísticas, registros imagísticos e visitas de campo, corroboram a história conservativa da fonte, associando-a às alterações urbanas. Espera-se contribuir para a qualificação das discussões da necessidade de interação dos órgãos públicos em ações voltadas à preservação das praças e monumentos paulistas.
\end{abstract}

Palavras-chave: conservação de bens culturais, arte pública, preservação urbana, praças de São Paulo, Nicolina Vaz de Assis

\section{Desafíos para la conservación del arte público en un entorno urbano: el caso de la Fuente Monumental de Sao Paulo, Brasil}

Resumen: La ciudad de São Paulo conforma territorio de múltiples valores y vicisitudes decorrentes de cambios en el uso de los espacios públicos, interfiriendo directamente en la conservación material de su acervo de obras públicas. Compartiendo el espacio con otros elementos urbanos siempre renovables, las obras artísticas, como su entorno se actualizan para los usuarios; pueden ser preservadas o destruídas. Analizando el proceso degradante y las categorías de acción conservativas operadas en la Fuente Monumental de la plaza Júlio Mesquita (1927), de la escultora Nicolina Vaz, este artículo tiene como objetivo suscitar reflexiones sobre la efectividad de las operaciones de conservación física de las esculturas públicas como acto desconectado de la lectura de los cambios de uso de los espacios. Investigaciones de archivos, los registros de imágenes y visitas de campo, corroboran la historia de conservacíon de la fuente, asociándola a las modificaciones urbanas. Se espera contribuir para la cualificación de las discusiones sobre la necesidad de interacción de los organismos públicos en acciones que apuntan la preservación de las plazas y monumentos de São Paulo.

Palabras clave: conservación de bienes culturales, arte público, preservacíon urbana, plazas de São Paulo, Nicolina Vaz de Assis

\section{The challenges facing the conservation of public art in an urban landscape: the case of the monumental fountain in Sao Paulo, Brazil}

Abstract: The city of Sao Paulo is a territory of multiple values and vicissitudes linked to the changes in the use of its public spaces that directly interfere with the material conservation of its collection of public art. Just by sharing the space with other ever-changing urban elements, those pieces of art, just like their surroundings, are also constantly updated for the passerby's; it can be preserved or even destroyed. By analyzing the process of degradation and conservative actions of the Monumental Fountain of the Julio Mesquita Square (1927), built by Nicolina Vaz, this article aims to offer reflections on the effectiveness of physical conservation acts of public art when detached of the study of changes of interaction with urban spaces. Archival research, field analysis and imagery resources, reaffirm the fountain's conservative acts history, associating it with its surrounding urban modifications. The article intends to contribute to enriching discussions on public official's need to interact conservative acts of monuments with adequate preservation of Sao Paulo's squares.

Keyword: cultural heritage conservation, public art, urban preservation, squares of São Paulo, Nicolina Vaz de Assis 


\section{Introdução}

Na Praça Júlio Mesquita, tem a estátua da lagosta. Quem passa de longe enxerga. Quem passa de perto gosta. Adoniran Barbosa e Tasso Bangel, 1979 ${ }^{[1]}$

Na concepção corrente, a noção de arte pública corresponde a arte realizada fora dos espaços tradicionais e institucionalmente dedicados a ela, as galerias e museus. Sua inserção no ambiente urbano, de forma permanente ou temporária, a torna fisicamente acessível a um grande número de pessoas que estabelecem com elas experiências individualizadas, permeadas por diferentes referenciais de ordem psicológica, social, política e cultural. Por compartilhar o espaço com muitos outros elementos das cidades, que mudam constantemente, os significados artísticos e/ou memoriais dessas obras também se atualizam para os fruidores urbanos, fator que incide diretamente na sua preservação física e/ou destruição.

A "Fonte das Lagostas", como é popularmente conhecida a Fonte Monumental, situada na Praça Júlio Mesquita, na área central de São Paulo, desde sua inauguração em 1927, pelo bem ou pelo mal, é considerada elemento notável da paisagem urbana paulistana. Nas primeiras décadas, distinguia-se por sua beleza e interação perfeita com o espaço que ocupava, em meio a uma avenida projetada para expressar a modernidade e cosmopolitismo da capital do estado, para nas décadas subsequentes, em detrimento das alterações da ambiência e atividades em seu entorno, aos poucos perder seu protagonismo como obra de arte. Há décadas os jornais noticiam a falta de manutenção, os atos de vandalismo, o roubo de peças integrantes do conjunto, entre outras concernentes à materialidade do conjunto escultórico, reclamando, justamente, providências para mantê-la em bom estado físico.

O centro da cidade de São Paulo é um espaço que conforma território de múltiplas situações e disputas que interferem diretamente na conservação da materialidade do grande acervo de obras públicas que o integra. Para além das polêmicas sobre manutenção (ou não) de estátuas relacionadas a personagens históricos controversos, retomadas com vigor em 2020, há de se refletir sobre a efetividade das ações de preservação física como ato desconectado da compreensão das mudanças de uso dos espaços centrais. Integrando parte de pesquisa acadêmica em desenvolvimento na Universidade Estadual de Campinas pelas autoras, o caso da Fonte Monumental se oferece para reflexões sobre possibilidades e limites da manutenção de outras obras escultóricas ao aberto atualmente sob a tutela do Departamento do Patrimônio Histórico (DPH-SP) da Secretaria Municipal de Cultura de São Paulo, em especial, por tratar-se de uma praça pública, que divide a responsabilidade de manutenção com outros órgãos da municipalidade.
O DPH-SP, desde 1975, tem sob sua tutela um importante acervo de obras artísticas e monumentos em espaços públicos que somam atualmente 377 obras implantadas em parques, canteiros de ruas e passeios, com concentração de exemplares escultóricos nas praças da cidade. Trata-se de conjunto com grande diversidade tipológica representada por bustos, marcos históricos, estátuas, fontes e também monumentos, alguns de relevância nacional, a exemplo do "Monumento às Bandeiras", do escultor ítalo-brasileiro Victor Brecheret ${ }^{[2]}$, um dos cartões postais de São Paulo. Por se constituir em representações artísticas relacionadas a diferentes períodos e âmbitos históricos e culturais, o acervo público em causa encerra significados memoriais e expressões sociais relevantes, ressaltando o caráter cosmopolita da cidade.

São Paulo é atualmente uma megalópole com 12,33 milhões de habitantes, e como tal é passível de contínuas e rápidas transformações no tempo. No dizer de Benedito Lima de Toledo: "A cidade de São Paulo é um palimpsesto - um imenso pergaminho cuja escrita é raspada de tempos em tempos, para receber outra nova, de qualidade literária inferior, no geral. Uma cidade reconstruída duas vezes sobre si mesma, no século XIX." (Toledo 2004: 77).

Até o século XVII, era uma pequena vila, com atividade econômica baseada na agricultura de subsistência, modestas construções de terra, estreitos caminhos e poucos habitantes. O desenvolvimento econômico impulsionado pela economia cafeeira foi paulatinamente mudando suas feições e, no final do século XIX, a vida na capital do estado, que se concentrava na área do centro comercial, começa a se expandir para outras regiões da cidade, principalmente norte e leste, em virtude da inauguração das linhas férreas. A Estação da Luz inaugurada em 1868, significou uma importante alternativa para a ligação entre a cidade portuária de $\operatorname{Santos}^{[3]}$ e as zonas cafeeiras no interior do estado, proporcionando uma reorganização expressiva do sistema viário urbano por estabelecer novas funções para outras áreas da cidade.

Com esse desenvolvimento viário instituíram-se ligações entre o centro comercial, áreas residenciais e estações ferroviárias, impulsionando a ocupação da região central e contribuindo para a formação do loteamento das regiões próximas, entre elas o bairro Campos Elíseos, primeiro empreendimento imobiliário a ter um padrão urbanístico inspirado nos modelos de habitação europeus, que com seus palacetes introduziam uma arquitetura representada por padrões neoclassicistas e ecléticos. Para a consolidação dos novos bairros foram implementadas infraestruturas urbanas que modificaram completa e substancialmente toda a região. Com o crescimento da cidade e a chegada da São Paulo Railwaye a Light and Power, Company Ltda, a cidade vai se modernizando. As linhas de bonde que antes eram de tração animal passam a ser movidas pela eletricidade, mostrando que São Paulo se industrializava e reclamava espaços condizentes com esta condição. Na gestão do Prefeito Antônio Prado (1899-1911) foram iniciados os 
grandes projetos de reformulação e modernização viária na área central da cidade.

[...] no cenário de construção da paisagem transformou os critérios e as exigências técnicas, sofisticando as obras e trazendo novas maneiras de se construir a forma urbana, como provava a lei que determinava a regulamentação das intervenções e as normas de instalação da rede de energia elétrica na cidade. (Rodrigues 2010: 89)

A partir da década de 1910 ocorre a implantação das primeiras praças públicas da cidade, impulsionando financiamentos para a colocação de esculturas ao aberto visando ao embelezamento urbano, inclusive com a instalação de reproduções de obras mundialmente conhecidas que chegavam ao Brasil pela escola Liceu de Artes e Ofícios de São Paulo ${ }^{[4]}$, constituindo-se em material de observação para estudos de composição e fazeres artísticos. Assim, réplicas de obras clássicas de escultores do século XV ao XVIII, a exemplo do David e o Moisés de Michelangelo Buonarotti, de Diana, a caçadora de JeanAntoine Houdon, e da Amaltéia e a Cabra de Júpiter de Pierre Julien passam a integrar as praças da capital paulista. Junto com as réplicas, disseminavam-se também obras escultóricas dos talentosos professores do Liceu, a exemplo de Amadeo Zani, Ettore Ximenes e Galileo Emendabili cujas obras integravam as praças da cidade.
A Fonte Monumental da Praça Júlio Mesquita, implantada na avenida São João, importante artéria viária da cidade, integra e testemunha um marcante episódio de crescimento de São Paulo, que junto a outras vinte e uma praças com esculturas da área central [figura 1] sob a tutela do DPH-SP, precisam ser analisadas em acordo com as alterações do lugar em que se inserem e de seus valores de ambiência sempre repropostos.

A fonte é de autoria da renomada escultora Nicolina Vaz de Assis Pinto do Couto (1874 - 1941), primeira mulher a ter uma obra pública escultórica monumental na cidade de São Paulo. Implantada em 1927, a fonte em estilo art nouveau é uma das raras fontes da metrópole. Ao longo dos seus mais de noventa anos de existência, passou por diversas intervenções de conservação e restauro que, bem ou mal realizadas, garantiram sua manutenção no local até os nossos dias, ainda que isso tenha lhe custado a substituição de seus elementos em bronze e a proteção com placas de vidro, conforme se verá neste texto.

\section{A Fonte Monumental de Nicolina Vaz de Assis}

O campo das artes no Brasil no início do século XX era uma das áreas em que poucas mulheres tinham a oportunidade de trabalhar e ter reconhecimento profissional, em especial

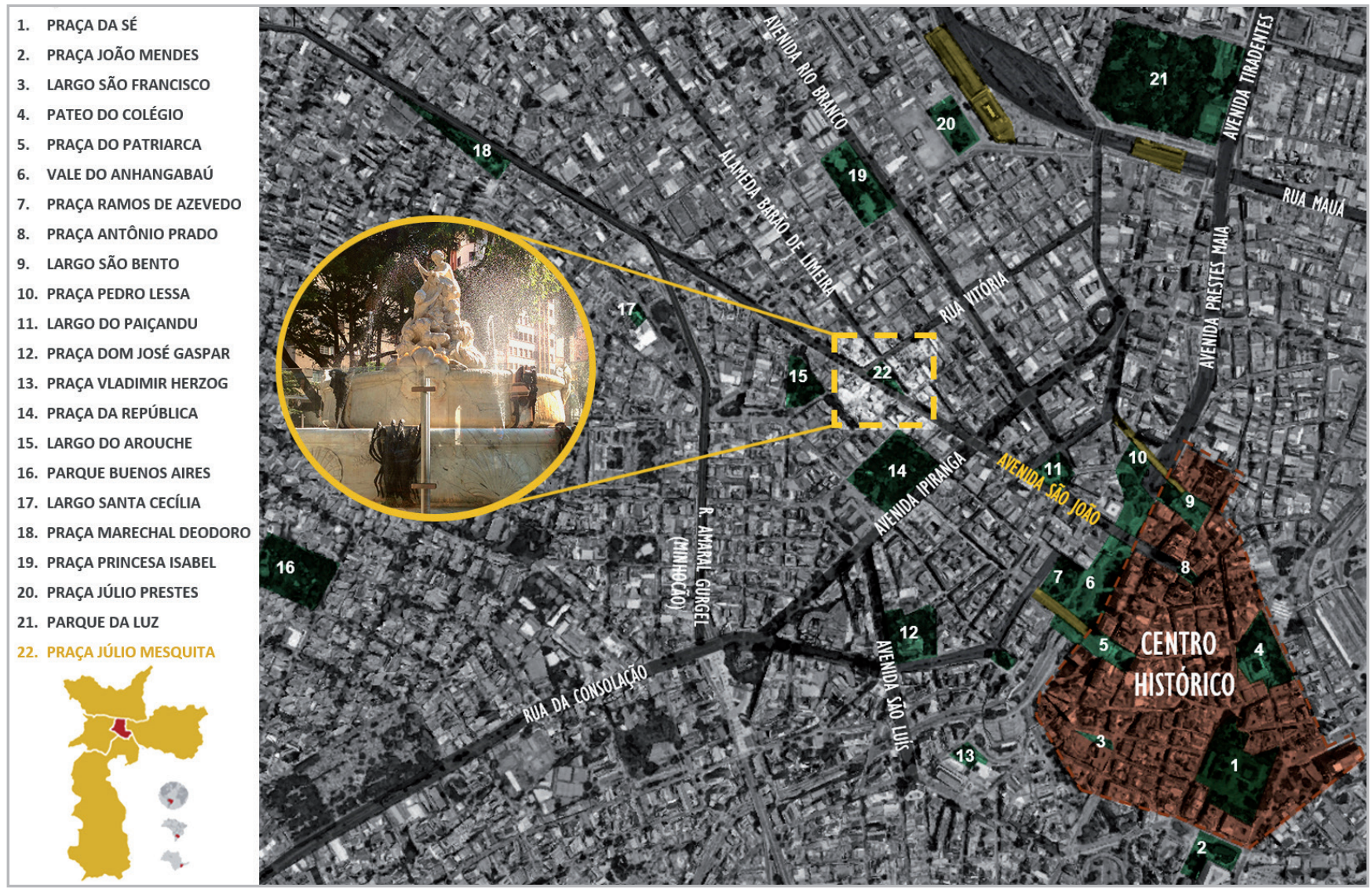

Figura 1.- Demarcação das vinte e duas praças na área central de São Paulo que contam com obras artísticas e monumentos sob a guarda do DPH-SP. A Praça Júlio Mesquita (22), está localizada na avenida São João. Elaborado por Alice Américo, a partir do Google Maps, 2020. [consulta: 3/7/2020]. 
no âmbito da concepção e produção de esculturas, considerada então uma arte masculina que exigia força física. Não obstante suas dificuldades, devido a sua dedicação à arte, em 1897 Nicolina Vaz de Assis recebe incentivos financeiros do Governo do Estado de São Paulo para se aperfeiçoar na Escola de Belas Artes do Rio de Janeiro, atual Museu Nacional de Belas Artes (Simionl 2008: 263). Inicia-se sua promissora carreira de escultora, moldando obras tumulares em mármore ou fundidas em bronze, por encomenda de familiares, para a seguir trabalhar com grandes obras públicas.

Entre 1899 a 1933, a escultora expõe suas obras em várias edições da famosa Exposição Geral de Belas Artes no Rio de Janeiro [figura 2], recebendo duas menções honrosas, em 1901 e 1902, e medalha de prata e ouro em 1907 e 1908 (Kurten 2014). Posteriormente, Nicolina foi para Paris tendo a oportunidade de estudar com importantes escultores e pintores da época, entre os quais Jean Alexandre Joseph Falguièree Denys Puech. Neste período participa da exposição anual parisiense e conhece o seu segundo marido, o professor e escultor português Rodolfo Pinto do Couto, autor de obras famosas como o monumento a Eça de Queiroz, no Rio de Janeiro e a arte tumular do senador Pinheiro Machado, no cemitério da Santa Casa de Porto Alegre.

No Brasil, a escultora produziu diversas obras particulares, com destaque para a escultura O Selvagem, realizada para o túmulo de um dos presidentes da Província de São Paulo, o Sr. José Vieira Couto de Magalhães, localizada no Cemitério da Consolação, em São Paulo - considerada o primeiro exemplar de escultura art nouveau na cidade. Assis também se dedicou a obras públicas que foram implantadas em jardins, parques e praças, sendo consideradas suas principais obras o Canto das Sereias, da Quinta da Boa Vista, no Rio de Janeiro, e a Fonte Monumental.

A Fonte Monumental [figura 3], sua obra mais notável, integrava o projeto de urbanização do prefeito Antônio Prado, já mencionado, que previa a construção de um "Centro Cívico" para compor a esplanada ajardinada do Largo da Sé.

Com a finalidade de embelezar essa esplanada, a Lei no 1742 de 18.9.1913 autorizava a Prefeitura a aceitar a proposta da escultora brasileira residente na Europa, Nicolina Vaz de Assis Pinto do Couto (Campinas, 1874 Rio de Janeiro, 1941), para a confecção "de uma fonte em mármore branco de carrara e bronze dourado a fogo", para ser colocada na praça ajardinada que deve ficar em frente à nova Catedral ou em outro ponto conveniente da cidade. (Antunes 2010: 5)

Nesse projeto previa-se a demolição de edificações localizadas no antigo Largo da Sé e do seu entorno para a construção de novos edifícios públicos: a Nova Catedral, o Paço Municipal, o Palácio da Justiça e o Congresso. Na revisão do projeto, as edificações propostas não foram levadas a termo, só a Catedral foi construída. A escultora foi contratada pela municipalidade para a realização da fonte. No entanto, devido à problemas com a empresa que executaria as peças de mármore, a prefeitura decidiu por realizar uma ampla concorrência pública para a contratação dos serviços de montagem a partir das peças que viriam da Itália, e também a contratação de um especialista em fundição de bronze para a execução das

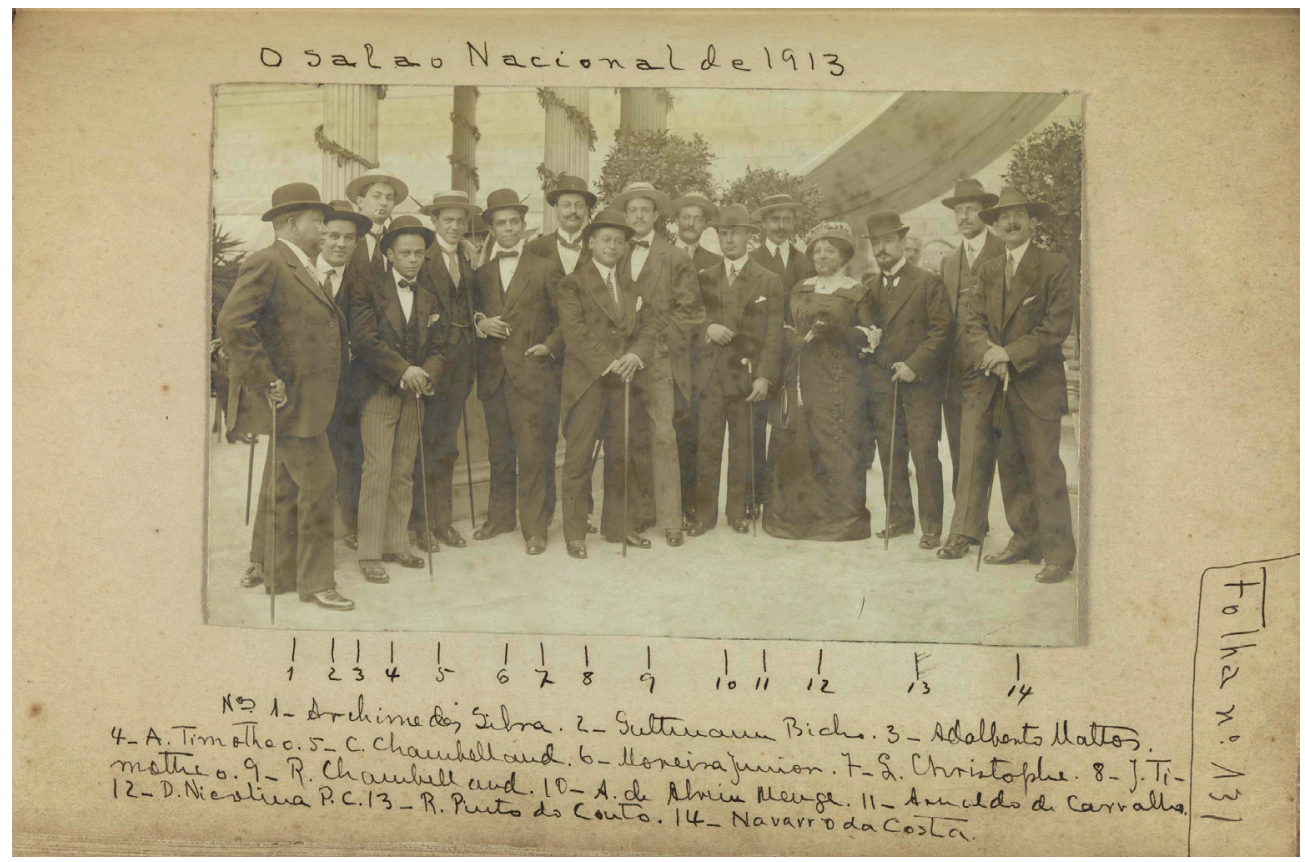

Figura 2.- Nicolina Vaz de Assis ao lado de seu marido e de outros grandes escultores da época na Exposição Geral de Belas Artes no Rio de Janeiro, em 1913. Acervo da Biblioteca Nacional. http://objdigital.bn.br/objdigital2/acervo digital/div iconografia/icon276572 276573/ icon1419029.jpg. [consulta: 4/7/2020. 
máscaras e das lagostas, que ficaria a cargo do escultor Roque de Mingo.

Devido a morosidade da execução, a instalação da Fonte Monumental em espaço público só veio a ocorrer em 1927, e em uma nova localidade, a praça Vitória, futura Júlio Mesquita. A fonte é composta por uma base octogonal de 8,28 metros x 8,28 metros, com duas vascas circulares sobrepostas, feitas em mármore de Carrara, que atingem 2,30 metros de altura ${ }^{[5]}$. O conjunto escultórico na segunda vasca, representa um jovem pescador que estende a sua rede para seduzir as sereias, despertando a atenção do espectador. No lado externo das vascas, ornamentos florais, conchas em mármore, máscaras com feições femininas e as famosas lagostas em bronze complementam os adornos da fonte. $\mathrm{Na}$ delicadeza da composição de Assis, se observa a serenidade com que são apresentados os personagens que compõe a obra [figura 3].

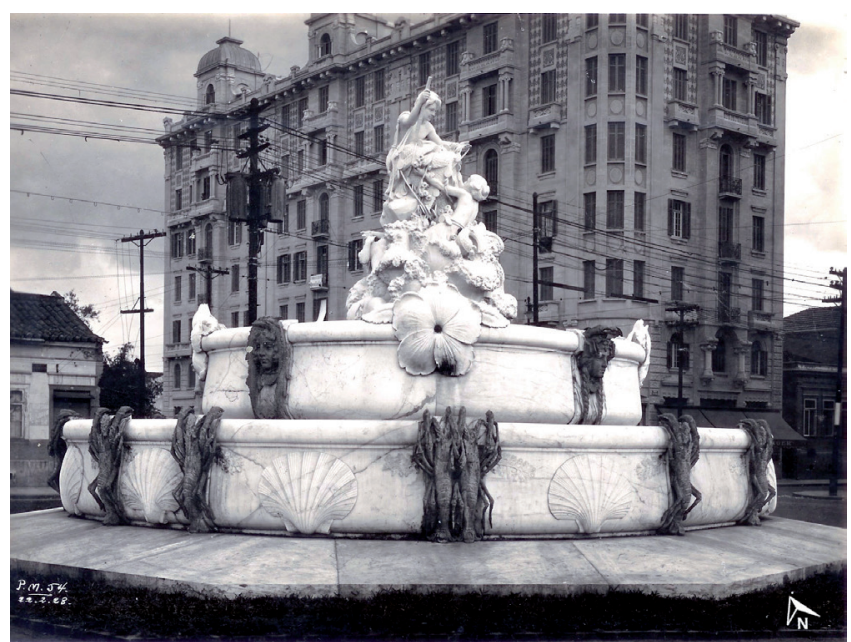

Figura 3.- Fonte Monumental na Praça Júlio Mesquita, um ano após a sua inauguração. Acervo Fotográfico do Arquivo Histórico Municipal de São Paulo. http://www.acervosdacidade.prefeitura. sp.gov.br/PORTALACERVOS/ExibirltemAcervo.aspx?id=606341. [consulta: 8/8/2019].

\section{A praça Júlio Mesquita, suas transformações e a degradação da fonte}

Entre os projetos de reformulação urbana de São Paulo no início do século XX, incluíam-se as obras de alargamento da Rua São João, uma artéria viária importante para a cidade, que transformaria a rua na atual avenida São João, com cerca de 2,6 km de extensão.

Em 1911, em perspectiva haussmaniana[6], o alargamento de trinta metros em linha reta implicou necessariamente em muitas desapropriações e demolições de edificações antigas do bairro. A avenida São João, projetada como um boulevard nos moldes parisienses, veio a tornar-se importante ligação entre a região central e oeste da cidade, em direção aos bairros dos Campos Elíseos e Barra Funda. O trilho de bonde implantado nos dois lados da via potencializava seu papel de eixo viário de uma cidade em transformação [figuras 4-b e 4-c], que com a construção de edifícios altos de orientação classicizante e a implantação de espaços verdes planejados, se afirmava como um aprazível boulevard. Tais mudanças trouxeram novas ocupações para a avenida e seu entorno, com abertura de cafés, teatros, lojas, e a partir da década de 1920 cinemas, que fez com que anos mais tarde a região fosse conhecida por "Cinelândia".

Novas praças foram concebidas ao longo desse eixo, entre elas a Praça Júlio Mesquita, confluência da atual avenida São João com a alameda Barão de Limeira, local que em 1927 viria a abrigar a Fonte Monumental [figuras 4-a e 4-b], como um novo respiro da futura metrópole. "O reconhecimento da suma importância da água junto ao verde da metrópole revela-se no surgimento de um novo termo técnico na construção urbana - a água decorativa" (Sitte 1992: 166).

Apesar da obra escultórica de Nicolina ter sido projetada para ocupar o Largo da Sé, a observação e a boa fruição da Fonte Monumental se favoreceu com a posição em que foi implantada na Praça Júlio Mesquita, resultando em uma composição especialmente adequada para valorizar um ponto de bifurcação importante da nova avenida. À época, a fonte efetivamente compunha a paisagem urbana, enaltecida pelas ruas perpendiculares que na linha de visão corresponde a um ponto de fuga na perspectiva da praça [figura 4-c].

Dando especial lugarà FonteMonumental, a pequena praça foi projetada e executada com esmero, sem equipamentos que

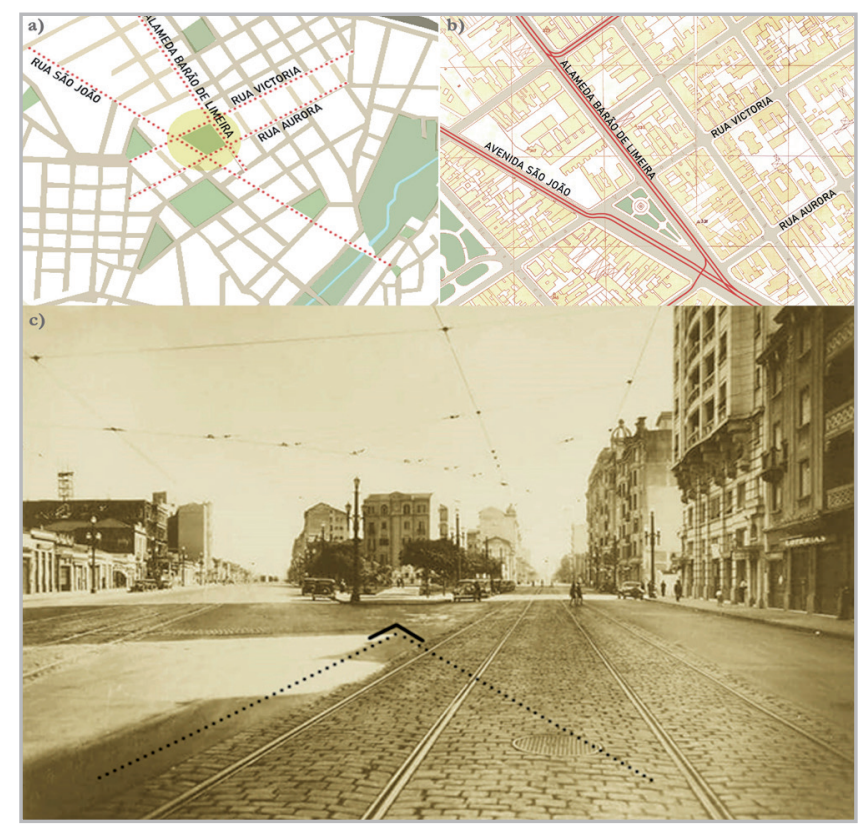

Figura 4.- a) Em amarelo destaque para o lote em verde que receberá a Praça Vitória, anos mais tarde. Em tracejado vermelho, as ruas: São João, Victoria, Aurora e alameda Barão de Limeira. b) Apresenta-se a transformação da Rua São João em avenida, com destaque em vermelho para as linhas de bonde, e a confluência entre a avenida São João e a alameda Barão de Limeira que definem o desenho da praça Júlio Mesquita (antiga Praça Vitória) em verde.c) Na perspectiva visual da Praça e de sua fonte ao centro $(1936)^{[7]}$. 
obstaculizasse os eixos de passagem pedonal, permitindo que a obra pudesse ser observada em $360^{\circ}$ pelos transeuntes da avenida. Contava com pavimentação decorativa em mosaico português e palmeiras baixas delimitando os canteiros gramados, aos moldes dos jardins parisienses [figura 5-a]. Tratava-se de um ponto tradicional de praças, destacando em seus objetos artísticos e vistas circundantes, uma composição clássica, conforme Camillo Sitte.

Logo, à regra antiga de dispor os monumentos ao longo das bordas das praças, soma-se aquela de caráter nórdico, genuinamente medieval: os monumentos, em especial os chafarizes, devem ser dispostos em pontos intocados pelo trânsito da praça. (Sitte 1992: 38)

Na parte noroeste da praça [figura 5-a], havia casas modestas, dois sobrados de uso comercial e habitacional, e um edifício de cinco andares. Na década de 1930, as duas casas [figura 5-a] foram demolidas, possibilitando a construção da outra metade da edificação que iria se transformar no Palacete Lugano (edifício residencial com comércio notérreo), existente ainda hoje, ao lado dos dois sobrados remanescentes. O Edifício mais alto do entorno da praça nessa época era o Urca Hotel [figura 5-b], com os seus 7 andares, um hotel de luxo que

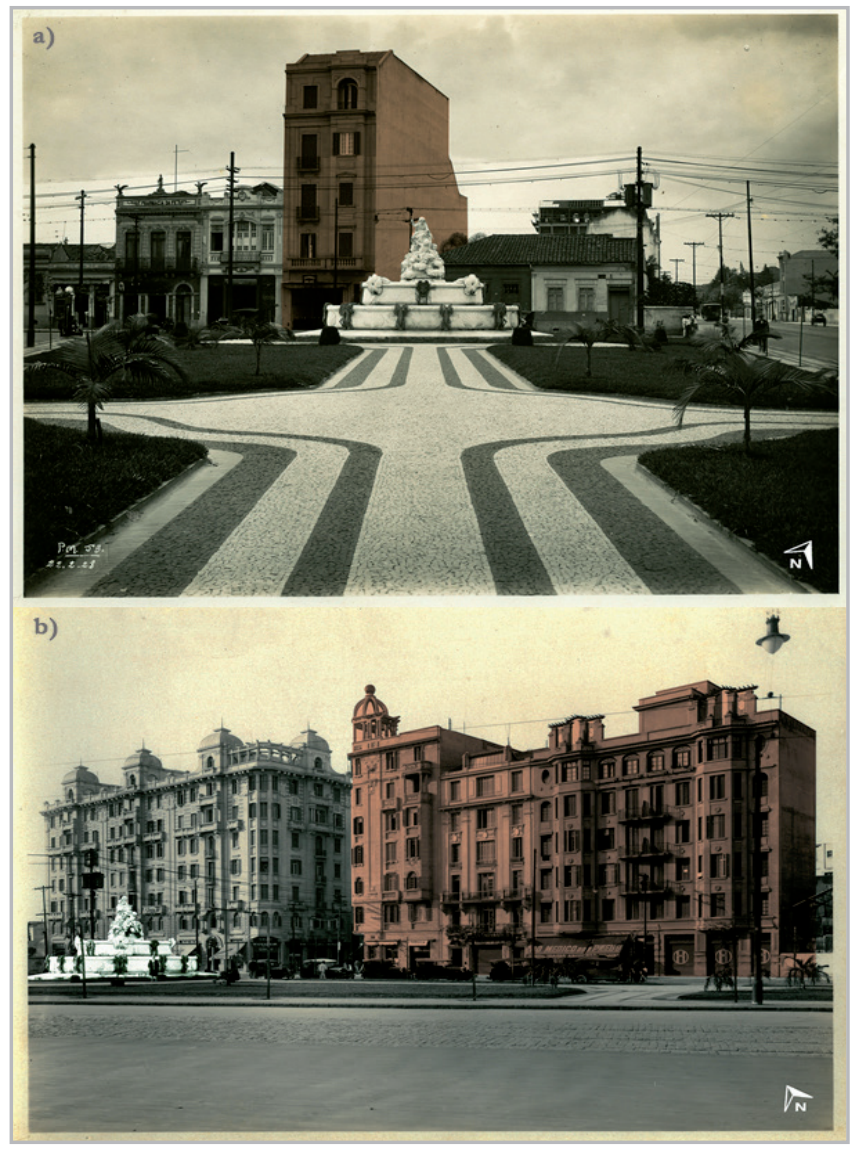

Figura 5.- a) Um ano após a inauguração da fonte, a partir do eixo monumental. Destaque em vermelho para o Palacete Lugano. Fotografia de 1928 com alterações de Alice Américo. Acervo Seção Técnica de Manuscritos, AHM/SMC/PMSP. b) Vista lateral da fonte a partir da avenida São João, e ao fundo em destaque em vermelho o prédio do Urca Hotel. Fotografia de 1929 com alterações de Alice Américo. Acervo Seção Técnica de Manuscritos, AHM/SMC/PMSP. recebia personalidades importantes que visitavam a cidade, e que como muitos outros prédios de orientação estilística francesa, caracterizava a paisagem urbana da região.

As obras da avenida São João acarretaram mudanças substantivas na paisagem local, passando a existir normas edilícias especiais para assegurar um certo padrão volumétrico. Muitas edificações foram demolidas e em 1934 houve forte incentivo para a verticalização da área a partir do Ato Municipal no $663^{[8]}$, que autorizava a construção de edificações de 50 e 80 metros de altura nas avenidas mais largas, de modo a modernizar e transformar a paisagem urbana construída daquela região.

Na década de 1930, a praça recebe postes de iluminação no estilo inglês e um gradeamento baixo para a proteção do jardim [figura 6]. Nota-se que já há a preocupação com a proteção e preservação do bem público, uma tentativa de evitar danos na fonte e até mesmo no seu jardim. O desejo de proteção da materialidade da obra se faz notar pelos usuários que começaram a usar a praça como lugar de permanência e não apenas de passagem, como quando a fonte foi instalada. Em 1927 ela era um atrativo na cidade. As pessoas transitavam ao redor da fonte, tiravam fotos e admiravam seus jatos d'água. Com o tempo, a população vai estabelecendo uma relação mais próxima com a obra de arte, sentando-se em suas vascas, a exemplo das crianças da vizinhança, que primeiro atraídas pela água, passam também a utilizar suas vascas de mármore como lugar de recreação.

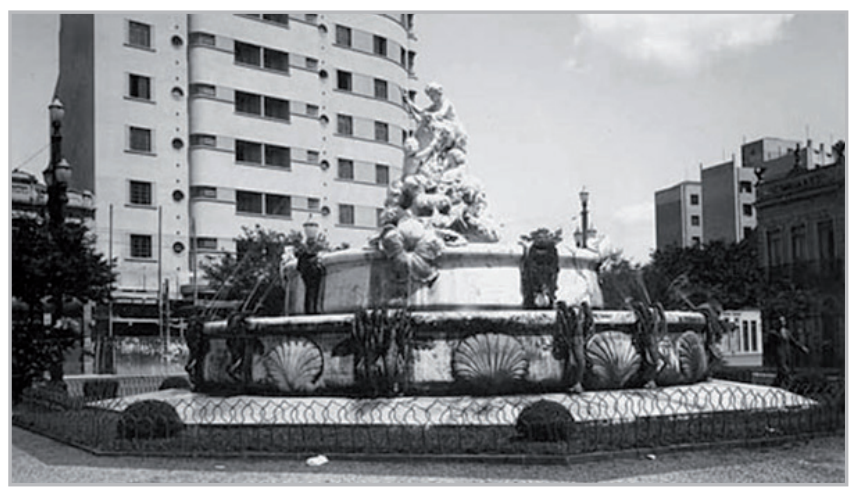

Figura 6.- Fotografia do período de 1930-39. Acervo Seção Técnica de Manuscritos, AHM/SMC/PMSP.

Entre 1960 e 1970, segundo dados censitários, a população de São Paulo cresceu de 3.825.351 para 5.978.977 habitantes em uma década. Em decorrência da especulação imobiliária na área central, somada a equivocados planos urbanísticos, a partir da década de 1970 a região entra em franco declínio, resultando em grande desvalorização de seus imóveis e, em consequência, mudança considerável dos modos de vida do espaço urbano.

Com a construção e inauguração em 1971 do Elevado Costa e Silva - via expressa elevada do complexo viário de ligação do trecho Leste-Oeste da cidade, popularmente conhecido como Minhocão - ocorre a transferência do fluxo de veículos 
da avenida para o elevado. Esse esvaziamento, aliado aos processos sociais de seu entorno, fizeram com que a praça Júlio Mesquita e outras deste mesmo eixo sofressem consideráveis modificações, que terminaram incidindo diretamente na conservação física da arte pública local, o modelo tradicional de praça deixa de ter importância como espaço de convívio social e de contemplação da arte. "Nas cidades antigas, as praças principais eram uma necessidade vital de primeira grandeza, pois ali tinha lugar uma grande parte da vida pública, que hoje ocupa espaços fechados em vez de praças abertas". (Sitte 1992: 198)

A avenida São João começa a perder o seu protagonismo na capital paulista. $\mathrm{O}$ eixo de desenvolvimento foi transferido para a região da avenida Paulista, e os primeiros sinais de abandono do centro não tardaram a aparecer, expressos também na degradação de suas estruturas e equipamentos urbanos. Trata-se de uma categoria de negligência e descuido que incide na casuística conservativa da Fonte Monumental, conforme avalia-se a seguir.

\section{As medidas de preservação da fonte monumental}

Foi no início da década de 1970 que alguns dos principais jornais do estado de São Paulo começam a publicar notícias referentes a deterioração da Fonte Monumental e descuido por parte do poder público. Problemas como a falta de água, quebra e furto de elementos decorativos, crianças brincando na fonte e se apoiando nos detalhes em bronze, como se a obra de Nicolina fosse apenas mais um elemento na praça.

O então abandono em contraste com o protagonismo que a fonte teve no início do século XX inspiraram Adoniram Barbosa (1910-1982), notável sambista brasileiro, a compor a música Roubaram a lagosta, ao lado do compositor Tasso Rangel:

Na Praça Júlio Mesquita / Tem a estátua da lagosta. / Quem passa de longe enxerga. / Quem passa de perto gosta. / E a lagosta de bronze / Fica esperando bom dia / Mas tem gente distraída / Que nem pra ela espia / Por uma razão muito forte / Ela em bronze foi lembrada / Inauguração na praça / Uma fita foi cortada. / Teve discurso, foguetes, / Teve churrasco e bebidas, / Teve mágicos e palhaços / Futebol, flerte e corrida. / Mas isso ficou para trás / Não sei que forma que tinha / Essas coisas não se faz / Agulha não vai sem linha. / Deixe a lagosta em paz / Muito bom ficar sozinha / Mas é melhor ficar seca ou molhada / Do que ser derretida ou roubada. (Santos 2006: 249)

Em 1984, o grupo do jornal O Estado de São Paulo decide realizar a manutenção da obra e de sua praça, em razão do local homenagear o nome de seu fundador. No entanto, apesar da manutenção realizada pelos empresários, a falta de uma proteção efetiva não impediu que o monumento sofresse novamente ações de depredação e pichações. $\mathrm{Na}$ tentativa de solucionar o problema, na gestão do Prefeito
Jânio Quadros (período 1986 - 1988), determinou-se que a Fonte Monumental e outros monumentos paulistanos fossem protegidos com grades. E assim, gradeada, a fonte de Nicolina permaneceu até 2004 [figura 7].

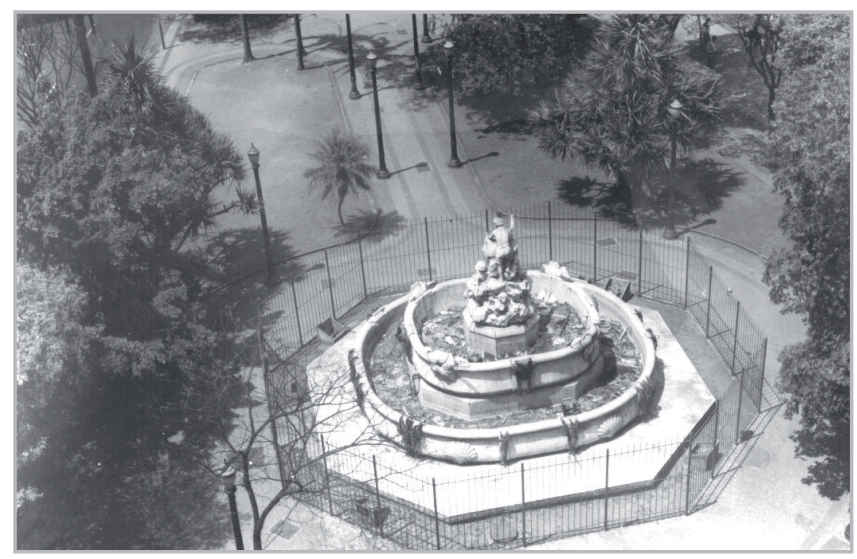

Figura 7.- Fonte Monumental gradeada. Acervo Seção Técnica de Levantamento e Pesquisa, DPH/SMC/PMSP, 1995

Contudo, não obstante essa medida de proteção física e pequenas obras de valorização da praça, ao longo dos anos a região já não era mais a mesma, e mesmo gradeada, a fonte começa a viver o auge da sua deterioração. Era possível encontrar dejetos, lixos e água contaminada, e os primeiros elementos decorativos em bronze começaram a desaparecer. A grade não impediu que todas essas ações ocorressem, os problemas na região eram muito mais graves, com causas majoritariamente sociais que afligiam todo o centro da cidade. A grade, além de não proteger, se tornou uma barreira visual, prejudicando a leitura e fruição da obra pelo transeunte.

Em 2004, o Departamento do Patrimônio Histórico (DPH-SP), por meio do parecer técnico da Comissão Permanente de Análise de Assuntos Concernentes a Obras e Monumentos Artísticos em Espaços Públicos, acordou com a Subprefeitura da Sé - órgão técnico municipal responsável pela área - a remoção das grades. Restabeleceu-se a fruição entre a fonte e a praça foi reestabelecida, mas as ações de depredação continuaram sem solução. Conforme imagens de 2009 e de 2011 [figuras 8-a e 8-b] a fonte parou de funcionar e todos os elementos ornamentais em bronze foram suprimidos.

Em 2010 foi contratado um projeto de restauro pelo DPHSP, concretizado somente em 2013, com recursos provindos do Fundo de Desenvolvimento Urbano (Fundurb), financiamento que permitiu à prefeitura municipal de São Paulo restaurar a fonte. Os serviços especializados de restauro contemplaram limpeza cuidadosa, remoção dos elementos espúrios e de intervenções inadequadas realizadas anteriormente, consolidação e reintegração de lacunas superficiais do mármore, aplicando-se, por fim cera microcristalina para proteção de todo o conjunto escultórico. A remoção de pichações foi obtida com aplicação cuidadosa, e pontual, de produtos químicos adequados a materialidade do bem e, visando a remoção de sombras remanescentes das pichações e sujidade 


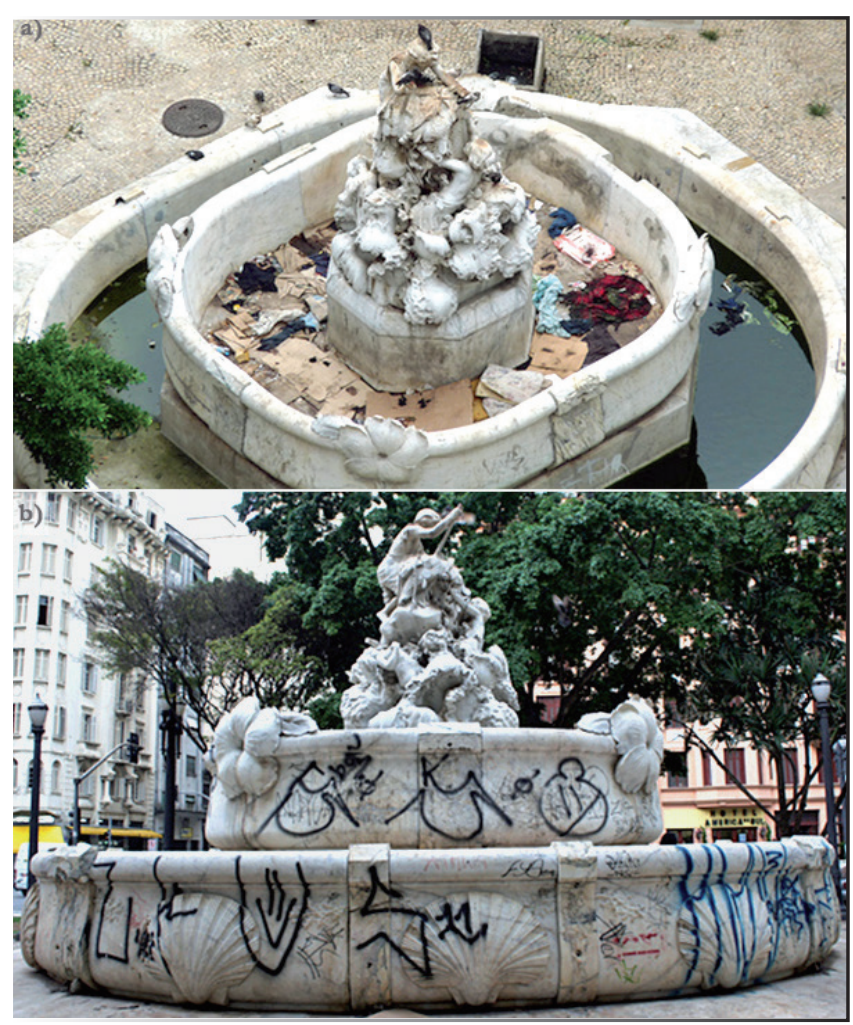

Figura 8.- a) Fonte Monumental em 2009. b) Fonte Monumental em 2011, sem as lagostas e com pichações no mármore. Fotografias do site São Paulo Antiga. http://www.saopauloantiga.com.br/ abandono-monumental e http://www.saopauloantiga.com. br/o-monumento-que-a-prefeitura-de-sao-paulo-abandonou/. [consulta: 10/07/2019].

aderida, foi aplicado microjateamento controlado. Os elementos decorativos faltantes foram reproduzidos reproduzidos, adotando o conceito de réplica de partes para recompor visualmente o conjunto. Para tanto, as peças originais de bronze faltantes - as lagostas e as máscaras foram reproduzidas em material sintético (fibra de vidro), enquanto as duas lagostas originais remanescentes foram armazenadas no depósito do DPH-SP. Os sistemas elétricos e hidráulicos da fonte foram reparados; ocasião em que foi projetado um novo tipo de isolamento físico para o conjunto escultórico: foi cercado por placas de vidro temperado para garantir proteção à fonte, considerado mais "harmônico" por conta da transparência do vidro.

Mesmo após esse restauro, em menos de dois anos o conjunto escultórico já apresentava sujidade aderida e pontos específicos em que seria necessário reintegração, ou seja, refazimento do restauro. Nesse período também foram furtados vários elementos, entre eles: luminárias, cabeamento, bomba e filtro da fonte e bicos em aço inox. Ademais, grande parte dos vidros do novo gradeamento da fonte já estavam quebrados. Em 2016 a obra foi novamente restaurada [figura 9-a], refazendo os mesmos serviços realizados anteriormente, com exceção da execução de novos elementos decorativos, que estavam em bom estado de conservação. Foram substituídos todos os vidros quebrados e os elementos hidráulicos e elétricos faltantes para que se pudesse reestabelecer o funcionamento da fonte. Em ambas as restaurações adotou-se a vertente critico-conservativa, com o princípio de mínima intervenção [9], no entanto claramente não foram suficientes para manter a preservação da fonte. Passado apenas um ano desta segunda intervenção, ainda que em funcionamento, a fonte estava novamente sem iluminação e com parte dos vidros estilhaçados. Efetivamente, a conservação física da escultura não tem bastado para garantir sua preservação no tempo. Outras possibilidades tem que ser consideradas.

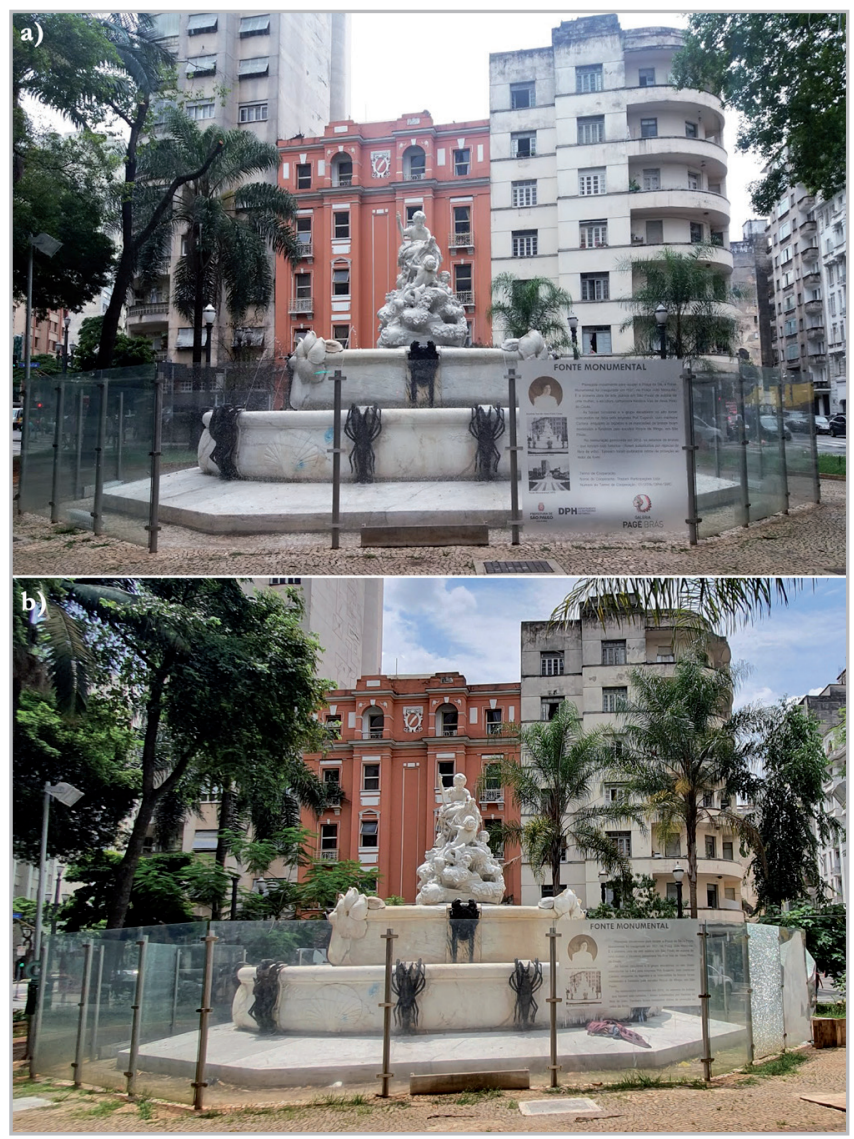

Figura 9.- a) Fonte após restauro em 2016. b) Estado de conservação atual da fonte, já com aspecto amarelado e com faces estilhaçadas da proteção em vidro. Fotografia: Alice Américo.

O isolamento em vidro, considerado em passado recente pelo DPH-SP uma boa solução como medida protetiva da fonte, de menor impacto visual que o gradeamento da década de 1980, confirmou-se apenas um paliativo, uma vez que é exposto a frequentes ações de vandalismo e a outros desgastes advindo de variadas ações cotidianas dos usuários. Conserva-se a escultura ou suas vidraças? A substituição constante das peças de vidro acabou se tornando insustentável. Em 2017, o DPH-SP, por meio da sua Comissão de Gestão de Obras e Monumentos Artísticos em Espaços Públicos, substituiu os vidros esfacelados pelo acrílico, que apesar de ser um material suscetível a riscos, é mais resistente que o vidro, dificultando a quebra das placas de isolamento.

Apesar de compreender por meio do estudo iconográfico e histórico da praça e de sua fonte a necessidade de se 
restabelecer sua fruição artística conforme planejada no início do Século XX, diante de tantas intercorrências negativas constata-se que enquanto não houver um plano de conservação efetivo e continuado para o local, decorrente de ações técnicas e educativas conjuntas entre os órgãos públicos municipais, envolvendo a própria comunidade, o isolamento com vidros ainda permanecerá "uma medida provisória" para conservar formal e materialmente a fonte. Mas até quando?

\section{Considerações finais}

O estado atual da fonte nos mostra que as ações efetivadas para a preservação da obra tiveram resultados apenas satisfatórios. A partir do histórico da Fonte Monumental, percebe-se que para uma preservação integral da obra não bastam ações emergenciais, executadas por meio de restaurações, é necessário estabelecer um plano de conservação que incorpore ações de políticas públicas integradas, que compreendam não apenas a fonte, mas a sua praça e o seu entorno. Os desafios atuais para a conservação deste espaço vão além do funcionamento ou não da fonte - o maior índice de reclamações. Solicitam planejamento de conjunto de ações que permitam retomar a praça como um espaço de convivência harmônica, com qualidades compositivas que impactam positivamente na percepção dos seus usuários. É necessário pensar na melhoria da qualidade de vida nas grandes cidades pelo resgate de espaços públicos e coletivos, pois sem pensar nos espaços urbanos em conjunto, os monumentos ao aberto nunca estarão completamente seguros.

Na Praça Júlio Mesquita, através das fotografias e descrições de antigos moradores, confirma-se o quanto aquele espaço era contemplativo, um raro lazer na cidade. Diferente de grandes cidades europeias, como Paris, Roma, Madrid, que possuem uma diversidade de fontes escultóricas no espaço urbano, São Paulo carece de espaços qualificados como esse, que permite uma apreciação artística e uma integração entre a população e o ambiente urbano.

As praças, que antes eram locais de apreciação da arte e importante local de convívio no espaço público, hoje são tratadas como qualquer espaço vazio entre as vias, sem significado. Com o isolamento cada vez maior das pessoas em seus apartamentos ou em seus próprios prédios, deixase de vivenciar o espaço público. A cidade é um sistema unificado, no qual a praça é local que impulsiona atividades coletivas, edevecontinuar cumprindo papel social.

Hoje, a Fonte Monumental em si, em seus aspectos materiais e estruturais, se encontra minimamente conservada. No entanto, todas estas experiências nos fazem refletir sobre o conflito entre a salvaguarda do patrimônio artístico e a aproximação da população com esse bem, uma conexão que deve voltar a ser garantida pela municipalidade. Será que um dia seremos capazes de unir as duas pontas desse problema e construir assim a solução? E qual é o limite da salvaguarda? É preferível ter a fonte no seu local original, onde sua relação artística e urbanística foi pensada, mesmo que sem o seu devido funcionamento? Certos questionamentos nos fazem refletir que tipo de cidade queremos e o que devemos fazer para preservá-la.

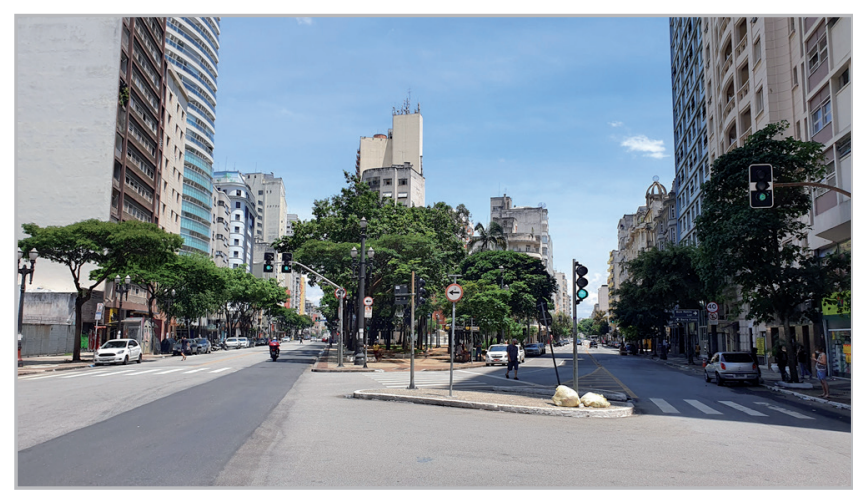

Figura 10.- Imagem realizada na mesma perspectiva da figura 4-c mostrando as alterações do entorno e a obstrução da visualidade da Fonte Monumental. Fotografia: Alice Américo, 2021.

\section{Notas}

[1] Trecho da Música “Roubaram as lagostas" (Santos 2006: 249).

[2] Victor Brecheret (1894 - 1955), escultor reconhecido e considerado inovador para os padrões artísticos paulistanos da época.

[3] Cidade portuária no interior do estado de São Paulo que desde o final do século XIX realiza a exportação de café. Hoje, corresponde a mais de $70 \%$ de todo o café produzido e exportado pelo Brasil.

[4] O Liceu de Artes e Ofícios de São Paulo se tornou referência nacional, com o intuito de "ministrar gratuitamente ao povo os conhecimentos necessários às artes e ofícios, ao comércio, à lavoura e às indústrias" (Liceu de Artes e Ofícios de São Paulo: missão excelência (2000). São Paulo: Marca D'água, p. 25).

[5] Departamento do Patrimônio Histórico (1987). Divisão de Preservação. Catálogo das obras de arte em logradouros públicos de São Paulo: Regional Sé. São Paulo: Departamento do Patrimônio Histórico.

[6] Identificado com a cultura urbanística europeia do século XIX e se vinculava com o maior exemplo de transformação urbana oitocentista. Urbanismo francês trazido por Pereira Passos, que viveu em Paris de 1857 a 1860, no auge das obras de Haussmann (Campos 2002: 136).

[7] Imagens elaboradas por Alice Américo a partir do extrato da Planta Geral da Capital de São Paulo de 1895, do mapa Sara Brasil de 1930, e fotografia de 1936 do Acervo da Seção Técnica de Manuscritos do AHM/SMC/PMSP, respectivamente.

[8] Ato do prefeito no 663 de 10 de agosto de 1934. http:// legislacao.prefeitura.sp.gov.br/leis/ato-gabinete-do-prefeito-663- 
de-10-de-agosto-de-1934. [consulta: 01/11/2019].

[9] Na dissertação de mestrado em andamento, este estudo de caso está sendo discutido com maior rigor técnico do ponto de vista da restauração.

\section{Referências}

CAVALCANTI SIMIONI, A. P. (2008). Profissão Artista: Pintoras e Escultoras Acadêmicas Brasileiras. São Paulo: Editora da Universidade de São Paulo / Fapesp.

KÜRTEN FENSKE, E. (2014). Nicolina Vaz de Assis - a escultora da belle èpoque tropical. Templo Cultural Delfos. http://www.elfikurten. com.br/2014/05/nicolina-vaz-de-assis-escultora-da.html. [consulta: 4/7/2019].

LIMA DE TOLEDO, B. (2004). São Paulo: três cidades em um século. 3. Ed. São Paulo: Cosac \& Naify, Duas Cidades.

MALTA CAMPOS, C. (2002). Os rumos da cidade: urbanismo e modernização de São Paulo. São Paulo: Editora Senac.

M. R. FERREIRA ANTUNES, F. (2010). Fonte Monumental. São Paulo, Seção Técnica de Levantamentos e Pesquisa da Divisão de Preservação do Departamento do Patrimônio Histórico da Secretaria Municipal de Cultura (DPH/SMC/PMSP), pasta $n^{\circ}$ 04A.038.0.

OLIVEIRA DA SILVEIRA SANTOS, L. (2006). São Paulo dá samba, uma visão de hospitalidade paulistana por meio do olhar de Adoniran Barbosa. Dissertação de mestrado do Programa de Hospitalidade da Universidade Anhembi Morumbi. São Paulo.

PARTEZANI RODRIGUES, G. (2010). Vias públicas: tipo e construção em São Paulo (1898-1945) / Gustavo Partezani Rodrigues. São Paulo: Imprensa Oficial do Estado de São Paulo.

SITTE, C. (1992). A Construção de Cidades Segundo Princípios Artísticos. Trad. Ricardo Ferreira Henrique. São Paulo: Ática.

\section{Autor/es}

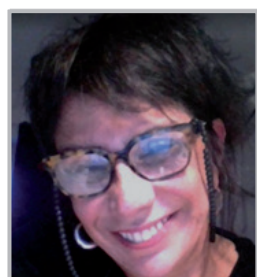

\section{Regina Andrade Tirello}

rtirello@unicamp.br

Universidade Estadual de Campinas, UNI-

CAMP - Campinas, SP - Brasil

Arquiteta. É docente na UNICAMP - Universidade Estadual de

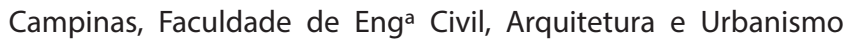
desde 2004, atuando nos cursos de graduação e pós-graduação. É Doutora pela Faculdade de Arquitetura e Urbanismo da Universidade de São Paulo (FAU-USP), com pós doutorado no Politecnico di Torino na área de Restauração e Valorização do Patrimônio. Foi coordenadora do programa Conservação e
Restauração de Bens Arquitetônicos e Integrados do Centro de Preservação Cultural da Universidade de São Paulo - CPC-USP (1989 a 2009). É líder do Laboratório de Conservação e Restauro da Arquiteura e Sítios (LCOR-Arquitetura) da Unicamp desde 2006. Desde 2020 é coordenadora do Programa de Pós-graduação Arquitetura, Tecnologia e Cidade (PPG-ATC) da Unicamp.

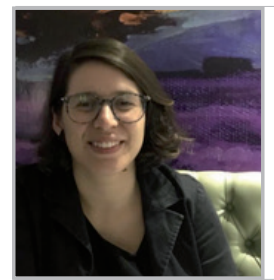

\section{Alice de Almeida Américo}

alice.aameric@gmail.com

Universidade Estadual de Campinas, UNICAMP - Campinas, SP - Brasil.

Arquiteta e Urbanista formada pela Universidade Presbiteriana Mackenzie, em São Paulo - Brasil (2015), com intercâmbio, através do Programa Ciências sem Fronteiras, na Università degli studi di Roma - La Sapienza, em Roma - Itália (2013), onde estudou Arquitetura e Urbanismo com ênfase na área de conservação e restauração de edifícios, monumentos e jardins históricos. Desde 2016 é Coordenadora do Núcleo de Monumentos e Obras Artísticas do Departamento do Patrimônio Histórico da Cidade de São Paulo (DPH-SP) e atualmente mestranda na Universidade de Campinas (Unicamp) do Programa de Pós-graduação “Arquitetura, Tecnologia e Cidade" (PPG-ATC). 